\title{
Theoretical and methodological principles of renewable energy development based on the technologies' transfer
}

\author{
Marta Manukhina ${ }^{1}$, Nataliia Riazanova ${ }^{2 *}$ \\ 1Volodymyr Dahl East Ukrainian National University, Department of accounting and taxation, \\ Severodonetsk, Ukraine \\ 2State Establishment "Luhansk Taras Shevchenko National University", Department of Finance, \\ Accounting and Banking, Starobelsk, Ukraine
}

\begin{abstract}
The article deals with the problems of economic provision of renewable energy development in interaction with innovation and technological elements: technology transfer, nanotechnology, intellectual environment for knowledge generation. The system of certain elements interaction in the form of innovation-technology consortium is analysed. The structure and composition of the engineering platform bases of the consortium are determined. Significant effects of nanotechnology projects in the field of renewable energy are formulated. The priority directions of scientific and technical policy in the relevant fields are proposed.
\end{abstract}

\section{Introduction}

Progressive growth rates of energy industry can be achieved both in extensive and intensive ways. The strategic aim of the innovation and science and technology policy in the energy sector is to create a sustainable national innovation system providing the fuel and energy complex with highly effective domestic technologies and equipment, scientific and technical and innovative solutions in the capacities necessary to support the country's energy security. However, it must be considered that the energy security of a certain state, based solely on its own innovative achievements, are more vulnerable than the energy security of countries that actively exchange technological benefits with partner countries on mutually beneficial terms. Hence, the interest in the development of renewable energy in the innovative-technological aspect significantly increase, which is confirmed by the highest level of growth in the use of non-traditional renewable energy sources among all energy sources in the world's balance.

\subsection{Relevance and problem of research}

\subsubsection{The purpose and objectives of the study}

* Corresponding author: natalirozez1975@gmail.com 
Creation of an innovative and technological and efficient energy sector that is adequate to the needs of a growing economy in energy resources, as well as international interests of the country, providing the necessary contribution to the socially oriented innovative country's development, is the main aim of the country's strategic development. Achieving this goal requires a consequent solution of the complex set of tasks, including: increasing the efficiency of reproduction, extraction and processing of fuel and energy resources to meet internal and external demands; upgrade and creation of a new energy infrastructure in close interaction with the intellectual environment that generates knowledge.

The main purpose of the paper is to develop methodological recommendations on the economic provision of renewable energy development and to assess its impact on related economic spheres in close interaction with innovative technological elements, namely, technology transfer and nanotechnology.

\subsubsection{The hypothesis of a scientific problem}

The hypothesis of the scientific problem is to substantiate the position that the reliance on the innovation and technological development of renewable energy sources is a single-option choice for the countries aimed at global competitiveness increasing. The growing role of innovation, technology transfer, and nanotechnologies in the renewable energy sources development is revealed in conjunction with the peculiarities of the fossil energy sources replacement with renewable ones in the most energy-efficient energy markets of the industrialized countries and with certain new challenges for the energy policy of Ukraine.

\subsection{Literature review}

Problems of economic innovation in the renewable energy sector have been considered by foreign scholars such as Daniel H. Yergin, Simon Roberson, Hugh Sharman, Mark Z. Jacobson, Ernst Schwanhold, Mark A. Delucchi, S. Tugsy, Ilhan Ozturk, Aslan Alper. Key aspects of cutting-edge innovative development, theoretical aspects of innovation, innovative cycles were considered in the work of such scholars as Joseph A. Schumpeter, Igor Ansoff, Viktor I. Kushlin, Konstantin I. Pletnev, Aleksandr N. Folmyev.

In Ukrainian economic and technical papers attention to the problem of the RES was paid by such scientists as V. V. Kostetskyi, S. O. Kudria, L Y. Matviychuk, A. V. Prokip, B. P. Herasymchuk Certain researches on the renewable energy, energy-saving technologies transfer and commercialisation of results of intellectual works were described in the publications of P. A. Drohovoz, P. N. Tsybuliov, Y. Lashyn, S. N. Shykaev. Some attention to RES issues and its influence on energy safety was paid by such scientists as A. A. Arbatov, A. M. Mastepanov, A. A. Konopelnyk, A. A. Makarov, O. B. Brahynskyi, K. N. Mylovydov.

Theoretical issues of the RES commercial effectiveness assessment take significant place in all mentioned above papers. Nevertheless, issues on technology transfer in renewable energy a scientifically based promotion of the innovations in the RES application. Developing of qualitative tools and obtaining of the representational results of mentioned problems solving are the most important factors for increasing global technological effectiveness in the countries that are leaders in the RES consumption.

\section{Results and discussion}

\subsection{Analysis of the situation}


The main subjects of social and economic interaction in the processes of modernization based on the innovation, technology transfer and nanotechnology, are, on the one hand, creative environments that provide knowledge generation, and on the other - production structures that create high-tech products and services. Problematic aspects of such interaction are the instrumentation of the transfer area between these subjects, low research and innovation activity of enterprises, traditionally "closed" industrial culture, which restricted with localized technological partnership. However, the focus on innovation, elaborated and existing models of the external innovations implementation, as well as culture, which makes innovations an indispensable element of the production consciousness, based on the successful work of modern $\mathrm{R} \& \mathrm{D}$ departments.

It is possible to build effectively general interaction architecture including a system of direct relationships connecting education, science, industry and business in the innovation process. Open innovation model is one of the tools for organisation of such interaction [1] In this case company relies not only on its inner R\&D products but actively involves innovations and competences from the outer environment. The understanding that "if we make the best use of internal and external ideas, we will win" is the basis of the open innovation paradigm is the [1; 2]. Industrial innovations' sphere is very sensitive for availability of its own R\&D products and how fast technological innovations are commercialized. [3;4] Crowd-sourcing tools that allow to create innovation accepted ideas' management and perform open contests, can be very useful for overcoming problems caused by increased level of the clients comfortability $[5 ; 6]$

Creation of consortium that consolidates environment of knowledge generation with environment where they are to be applied and provides deep engineering as result of interaction can be one of the way for innovation fracture overcoming. Within the frame of these consortia, the business groups of engineers, scientists and commercialization experts accompany and provide the production processes of energy saving technological innovations, and the research structures of universities and research institutes, together with R \& D departments of high-tech enterprises, carry out the development of innovative challenges facing the energy sector. The ideology of open innovation, implemented with the help of such organizations, can change the production and technological culture and dramatically increase the speed of knowledge metabolism as complex exchange processes, allowing the industry to reach new knowledge, transform them into technology or product, to include in economic turnover [15]

In future, effectively composed interaction system can accumulate significant flow of the twoway transaction, performed in the innovation system of Ukraine. As a potential global player on the market, it attracts particular interest of domestic and foreign investors and partners. It is worth to note the importance of establishing a network in our country that is responsible for coordinating the technological demands of the energy sector and technological proposals from the scientific community.

The structure, which has the form of innovative technology consortium. can be the basic organization form for the interaction system. Its institutional core should consists of: high-tech enterprises and organizations, innovative and research universities, venture companies, funds and agency organizations.

The institutional basis of the engineering platform of the consortium consists of the knowledge generation environment, the environment of their technology and the catalytic environment for development (Fig. 1)

Disciplinary basis of the consortium engineering platform is represented by a complex of innovative knowledge systems that are significant for its activities. They include energy systems of the future and modern materials, nanotechnologies. The content of the disciplinary basis is determined by structuring its matrix, as the identification of specific relevant areas for one or another significant innovative knowledge system (Table 1). Based on the disciplinary matrix, it is possible to segment thoroughly the innovative interests of high-tech companies and 
organizations as components of the consortium, including for foreign partners. Simultaneously, the problem of using the most promising personnel is solved here.

The consortium is a structure that combines, on the one hand, the innovative interests of a group of leading high-tech enterprises, and on the other - a large number of universities and research institutes. It is capable to organize network projects stimulating the creation of horizontal and vertical connections important for technology transfer [7; 16]. Such formation can become a powerful tool for innovation development, both in the technological and in the investment aspects.

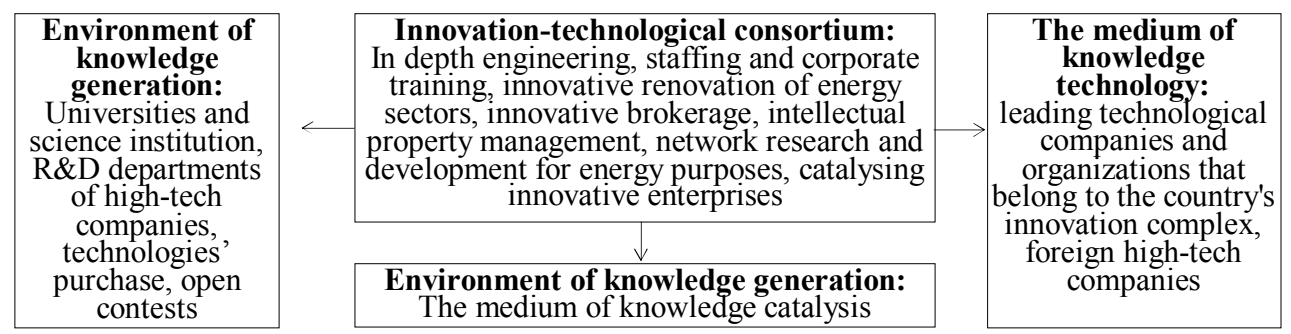

Fig. 1. Prototype of the institutional basis of the consortium engineering platform.

Table 1. Disciplinary basis of the consortium engineering platform.

\begin{tabular}{|c|c|c|}
\hline \multicolumn{2}{|c|}{$\begin{array}{l}\text { Innovatively significant } \\
\text { knowledge systems }\end{array}$} & Disciplinary matrix structuring \\
\hline \multirow[t]{3}{*}{1} & \multirow[t]{3}{*}{$\begin{array}{l}\text { Energy systems of } \\
\text { the future }\end{array}$} & $\begin{array}{l}\text { Renewable energy: solar, geothermal, wind and tidal, biofuels; technologies of } \\
\text { modern energy materials }\end{array}$ \\
\hline & & $\begin{array}{l}\text { Traditional energy industry: creation of inexpensive hydroelectric power } \\
\text { systems and thermal stations }\end{array}$ \\
\hline & & $\begin{array}{l}\text { Nuclear power industry: creation of compact sources of "eternal" energy; } \\
\text { power supply of space flights ; thermonuclear systems }\end{array}$ \\
\hline \multirow[t]{4}{*}{2} & \multirow[t]{4}{*}{$\begin{array}{l}\text { Modern materials } \\
\text { and } \\
\text { nanotechnologies }\end{array}$} & $\begin{array}{l}\text { Nanomaterials: structural and functional, including nanocomposites, which } \\
\text { strengthen nanocoatings, conducting nanoelectronic materials (synthesis, } \\
\text { diagnostics, use); high-purity substances }\end{array}$ \\
\hline & & $\begin{array}{l}\text { Nanoengineering: micro and nanosystem technology, nanoelectronics, } \\
\text { nanotechnology for energy production and management, nanometrology }\end{array}$ \\
\hline & & $\begin{array}{l}\text { Nanorisks: safety of nanomaterials and nanoproducts (the impact of } \\
\text { nanotechnologies and nanomaterials on human health during the development, } \\
\text { production, consumption and utilization periods) }\end{array}$ \\
\hline & & $\begin{array}{l}\text { The economy of the nanoscience: investments, high technology markets, } \\
\text { competitiveness, industrial structure }\end{array}$ \\
\hline
\end{tabular}

\subsection{Prospective of situation}

Prospects for the modern energy development, primarily for the renewable one, are related to the transfer of technologies and nanotechnologies, nanomaterials, consider their strategic importance as catalysts of innovative upgrade of the economy, the creation of powerful internal and external impulses and the effects of development, stimulation of sustainable growth not only in the field of energy, but also national economy in general. The continuous development of technology transfer and nanotechnology defines innovation and economic growth in virtually all industries, including renewable energy $[12 ; 15]$. The massive introduction of nanotechnologies will bring large-scale economic effects to the energy sector.

The main areas of effective use of nanotechnologies in the power industry are [13; 14]: use of renewable sources; energy storage; reduction of materials' consumption; use of alternative materials. Particularly relevant nanotechnologies in the field of energy storage and solar energy $[11 ; 17]$. Significant losses of electricity up to $4-9 \%$ in the Europe, $7-10 \%$ in the US and Canada, 
$13-14 \%$ in Ukraine during its transportation to the consumer are still the most significant problems of the development of the energy sector of the world economy [9; 10].

The main economic benefits of using nanotechnology in the field of energy are to increase the efficiency of materials and reduce production costs [8].

In the future, nanomaterials will allow to reach a significant increase in the capacity of batteries, the growth of efficiency and cheaper production of solar panels, prolonging the useful life of photovoltaic cells and storage batteries for large energy storage systems.

Hence, the most significant effects of the implementation of nanotechnology projects in the renewable energy sphere in the short-term and medium-term prospective, which are significant for the country's economy in general, will be:

- strengthening the country's energy security on the basis of increasing the use of RES with the depletion of traditional;

- increasing the efficiency of generating electricity by improving the technology of production and conversion of energy received from RES, increasing the volume of converted into electricity energy, reducing the duration of the processes;

- reduction of the cost of production of electric energy received from RES, as a result of: reduction of materials consumption and increase their efficiency in case of nanomaterials use, reduction of production costs;

- development and application of innovative systems of electric energy accumulation and storage, as well as new technologies of energy saving, increase of economic efficiency of the renewable energy sector;

- price decreasing in the wholesale energy market as result of rising proposition of renewable energy prices, that fully corresponds with consumers' interests;

- reduction of the negative impact of traditional sources on the environment and the neutralization of such negative costs by the use of innovative renewable energy technologies;

- obtaining economic advantages of the leader in the field of development of the latest technologies in this field by the country, providing an equal position in the market of high-tech energy products and services with a limited range of participants, as well as participation in the creation of global mechanisms for obtaining and redistribution of rent from the monopoly to unique knowledge and high technology.

\subsection{Recommendations}

The successful transfer of technologies in the energy sector requires certain conditions, the main ones of which can be attributed: a common, coordinated energy policy; the presence of a competent scientific and innovative authority in the industry; the common strategic vision for the development of the industry and the ways of integration.

Priority should be given to the following areas of scientific and technical policy in the relevant fields. In power industry: development of new and upgrade of existing technologies and technical means in order to increase the efficiency; increase of reliability and efficiency of the electric power transportation system, including creation of highly integrated intelligent systems and distribution electric networks of the new generation (Smart Grids); guaranteed uninterrupted power supply to consumers.

In the field of RES and local fuels:

- development of technologies for the RES usage, as well as multifunctional energy complexes for autonomous energy supply of consumers in areas disconnected from the centralized energy supply networks;

- development of effective technologies of network supply on the basis of RES;

- development of technologies of combined use of RES, as well as technologies of power generation unevenness compensation by generating objects on the basis of wind and tidal energy; 
- design and development of technologies for the modern materials use in the production of equipment and components for generating objects on the basis of RES in order to reduce the cost of their construction and increase the efficiency of functioning;

- expansion of production and use of new fuels derived from different types of biomass.

\section{Conclusions}

An important step in the implementation of the analysed problems is the creation of an innovation and technology consortium for the following tasks:

- organization of joint development and implementation of scientific and technical programs and innovative projects of consortium participants;

- assistance in determining of cooperation areas of mutual interest in the field of high technologies and innovations, based on national tasks and priority directions of scientific and technological, innovative and industrial development of participants;

- consolidation of effort of governmental authorities, public organizations expressing the interests of innovative business, entrepreneurs and commodity producers to increase the potential of high-tech branches of the economy as the basis of social and economic development;

- creation of conditions for attraction of investments to the innovative sphere.

Effective use of the capacities of fuel and energy complexes, as well as to provide national economies with the main types of energy resources, requires developing long-term mutually beneficial cooperation in the energy industry, technology transfer, and intellectual property, providing and pursuing coordinated energy policies, phasing the formation of common markets for energy resources based on the following principles: absence of technical, administrative and other obstacles to trade energy resources, equipment, technologies and related services; creation of favourable conditions for attraction of investments in the energy industry. The common market for energy resources creates an incentive for expert interest in the development of innovation, technology transfer, nanotechnology in the field of fuel and electricity transmission.

\section{References}

1. Chesbrough H. Open Innovation. Moscow: Pokolenie. (2007)

2. Denisov D. Business Journal. 6. (2011)

3. Schumpeter J. A. Business cycles. A theoretical, historical and statistical analysis of the capitalist process. 1. 220, (1939).

4. Andrew J. P., De Rocco E. S., Taylor A. The Innovation Imperative in Manufacturing:- How the United States Can Restore Its Edge. Boston: BCG, MI, NAM. (2009)

5. Yergin D. The Prize the Epic Quest for Oil, Money \& Power. Simon \& Schuster, New York, 945 (1991).

6. Sharman H. Renewables Won't Keep the Lights On. The Oil Drum.

7. Petrechenko V. (2010) Innovations: Switch on. Venture companies ecosystem of the harvesting cycle: Conditions and prospective. LLC "Nau-tech" M.: Business-journal; Computerra.

8. Building Connections, Fostering Solutions: 2012-2013ANSIAnnual Report. - New York, NY: ANSI, 40 (2013).

9. Russian nanotechnologies. 4, 11-12, 20-22 (2009)

10. Interview with Academician V. E. Fortov IV St. Petersburg International Economic Forum "Smart Networks - Smart Energy - Smart Economy". St. Petersburg, 2010.

11. German Energy Turn - Arguments for a Renewable Energy Future. Energytransition. The German Energiewende.

12. Energy efficiency mechanisms: energy industry innovations. NanoNewsNet. 12Th of January, (2011). 
13. Nanotechnology in the sectors of solar energy and energy storage. Technology Report / International Electrotechnical Commission. - Geneva, Switzerland : IEC, 101 ( 2013).

14. Make energy turning a successful project. Deutschland.de.1, 28-33 (2014).

15. Titov V. (2000) Transfer of Technology

16. Uskova O. (2011) Silicone Deadlock. Izvestiya. December 5

17. Tsybulov P. M, Intellectual Property Management. K.: "KIS”. 448, (2005) 